'Spotlight Article' in Trends in Cognitive Sciences

\title{
Gender equality and gender gaps in mathematics performance
}

Gillian R. Brown ${ }^{1}$ and Kim Alexandersen ${ }^{2}$

${ }^{1}$ School of Psychology \& Neuroscience, University of St Andrews, UK

${ }^{2}$ Department of Psychology, University of Stirling, UK

Correspondence: grb4@st-andrews.ac.uk (G.R. Brown)

Keywords: gender egalitarian, sex difference, maths, reading, science

\begin{abstract}
In a recent analysis of mathematics performance (Eriksson et al. 2020), national 'gender egalitarian values' were positively associated with an increase in the average maths scores of high-school boys relative to girls. This study highlights that progressive gender egalitarian values at a national level might not translate into equality of opportunity at an individual level.
\end{abstract}




\section{Main text}

The long-standing expectation that, on average, girls have lower mathematics abilities than boys has been undermined by several lines of empirical evidence; for instance, a meta-analysis has shown that the gender gap in average maths performance is close to zero [1], and the gap is reversed in around half of the countries for which national data are available [2]. However, the size of the gender gap in maths performance does vary across countries, which has allowed researchers to test the hypothesis that the gap is related to levels of gender equality in educational and economic opportunities. The hypothesis is that, in countries with lowest levels of gender equality, girls have reduced access to education, or are more likely to view maths as being irrelevant to their futures, compared to boys, resulting in lower relative female performance [3]. Consistent with this idea, the gender gap has been reported to be most male-biased in those countries with the lowest gender equality [e.g., 3,4]; however, this result has not replicated across all datasets [e.g., 2,3], suggesting that the relationship is not robust. Understanding the patterns in cross-cultural data on maths performance is relevant to ongoing debates about gender differences in participation in science-based careers.

The majority of studies on gender equality and academic performance have used measures of 'equality of opportunity' (based on data such as the proportion of women in the workforce or leadership positions) to quantify a nation's gender equality. In a recent study, Eriksson and colleagues [5] instead employed measures of 'gender egalitarian values', which are the cultural attitudes regarding the relative value placed on men and women, such as their right to work or leadership skills (Box 1). Eriksson and colleagues [5] argued that gender egalitarian values might better reflect the cultural factors that are most relevant to school-aged children. The study used data on maths performance in 14- to 15-year-old girls and boys from two international assessments of academic performance, spanning more than 6o countries (Box 1). The two-level, mixed-model regression analyses revealed that more gender egalitarian values corresponded with higher relative maths performance in boys compared to girls (i.e., a widening of the gender gap in countries with more 
egalitarian values). Eriksson and colleagues [5] also analysed the data on reading skills, which showed a large female advantage across all countries [5], and found that the gender gap was reduced in countries with higher gender egalitarian values. Thus, more gender egalitarian values were associated with an increase in the relative scores of boys in maths and a reduction in the female-biased gap in reading.

To interpret these results, Eriksson and colleagues [5] tentatively suggested that, in countries with more egalitarian values, school-aged children are less constrained by stereotypes of their own gender (e.g., the expectation that girls are more conscientious than boys) and more strongly experience those stereotypes associated with the opposite gender, resulting in girls putting less effort into their studies and boys being more studious. However, this interpretation does not explain why such gender stereotypes might initially arise. An alternative explanation, proposed by evolutionary psychologists in relation to other traits, is that males and females in gender equal societies have more freedom to express their 'innate', evolved psychological mechanisms [6], which are assumed to have diverged due to differential selection acting on males and females in ancestral human populations. However, this interpretation might have predicted that the gender gap in both maths and reading would expand with increasing gender equality values, which was the case for mathematics but not for reading, where average male scores became more similar to average female scores. Simplistic evolutionary accounts have been subject to a range of criticisms [7], and, in addition, the idea that gender socialisation processes are less influential in countries scoring high in gender equality measures than in countries with low gender equality remains an assumption; gender stereotypes have been shown to change over time without necessarily diminishing in strength [8].

Even though many questions about the cross-cultural patterns of academic performance remain unanswered, these data can also potentially shed light on how the relative strengths in different academic areas might influence the choice of subjects of boys and girls at school and university. Individual girls are more likely than individual boys to excel in reading relative to maths, 
whereas boys are more likely to exhibit higher relative strengths in maths than in language-based abilities [9]. Previous analyses have revealed that this gender difference in relative strengths (i.e., the difference between an individual's maths versus reading scores) is larger in those countries with higher gender equality [2], and the data presented by Eriksson and colleagues [5] are compatible with this general pattern (as the slope of the relationship between maths and gender egalitarian values is steeper than that for reading). In situations where the within-individual gap in relative performance is largest (which is most likely to be in more gender-egalitarian countries), girls might receive less encouragement to prioritise maths skills, whereas boys might receive more encouragement. Consistent with this interpretation, boys are reported to be more likely than girls to have lower average levels of maths anxiety, to have a positive attitude towards science-based subjects and to be more likely to over-estimate their science ability in more gender-equal countries [2,3]. Regardless of whether girls and boys differ in their intrinsic academic aptitude, these data suggest that gendered socialisation processes could exaggerate any differences and that progressive gender egalitarian values at a national level might not translate into equality of opportunity at an individual level.

The study by Eriksson and colleagues [5] provides a valuable contribution by raising the possibility that gender equality in some spheres could impact negatively upon gender equality in other aspects of society or at other stages of life. In addition, researchers might need to reflect on whether it is possible to predict a prior how gender equality will translate into equality of experience at an individual level; for instance, in the USA, the gender gaps in primary-school maths are male-biased regardless of the family's socioeconomic brackets and whether the mother is highly educated or in a maths-based occupation [10]. Further studies are needed to fully understand how gender stereotypes derived from parents, teachers, peers and the wider society influence children's gender-based perceptions of themselves and others. 
Box 1 Measures of gender egalitarian values and academic performance

Eriksson and colleagues [5] used two measures of 'gender egalitarian values', namely the World Values Survey (WVS) and the GLOBE project. The WVS is based on three items that state, 'When jobs are scarce, men should have more right to a job than women', 'On the whole, men make better political leaders than women do', and 'University is more important for a boy than for a girl'. Eriksson and colleagues [5] used averaged scores across 4 waves of the WVS that were carried out between 1994 and 2014, and data were available for 67 countries. The GLOBE project measured cultural practices and values in societies in the mid-1990s and provided data for 47 countries. The gender egalitarian values section of the GLOBE survey included several attitude statements, such as 'I believe that boys should be encouraged to attain a higher education more than girls' and 'I believe that opportunities for leadership positions should be more available for men than for women'. In their analyses, Eriksson and colleagues [5] controlled for a measure of gender equality in opportunity, namely the Global Gender Gap Index (GGGI), which has been used in previous studies on this topic [e.g., 2-4], and for the standard of living in the country. Therefore, the reported relationships between gender gaps in academic performance and gender egalitarian values were independent of these other country-level variables. The measures of academic performance used by Eriksson et al [5] were the Program for International Student Assessment (PISA) and the Trends in International Mathematics and Science Study (TIMSS) assessment, which provided datasets on 63 and 51 countries respectively. The main difference between these two datasets is the inclusion of a greater number of Middle Eastern countries in TIMSS compared to PISA [10].

\section{References}

[1] Voyer, D. and Voyer, S. D. 2014. Gender differences in scholastic achievement: a meta-analysis. Psych. Bull. 140: 1174-1204. 
[2] Stoat, G. and Geary, D. C. 2018. The gender-equality paradox in science, technology, engineering, and mathematics education. Psych. Sci. 29: 581-593.

[3] Else-Quest, N. M., Shibley-Hyde, J. and Linn, M. C. 2010. Cross-national patterns of gender differences in mathematics: a meta-analysis. Psych. Bull. 136: 103-127.

[4] Guiso, L., Monte, F., Sapienza, P. and Zingales, L. 2008. Culture, gender, and math. Science 320: $1164-1165$.

[5] Eriksson, K., Björnstjerna, M. and Vartanova, I. 2020. The relation between gender egalitarian values and gender differences in academic achievement. Front. Psychol. 11: 236.

[6] Schmitt, D. P. 2015. The evolution of culturally-variable sex differences: men and women are not always different, but when they are... it appears not to result from patriarchy or sex role socialization. In: The Evolution of Sexuality, ed. T. K. Shackelford and R. D. Hansen. Springer. Pp. 221-256.

[7] Bolhuis, J. J., Brown, G. R., Richarson, R. C. and Laland, K. N. 2011. Darwin in mind: new opportunities for evolutionary psychology. PLoS Biol. 9: e1001109.

[8] Eagly, A. H., Nater, C., Miller, D. I., Kaufmann, M. and Sczesny, S. 202o. Gender stereotypes have changed: a cross-temporal meta-analysis of U.S. public opinion polls from 1946 to 2018. Am. Psychol. 75: 302-215.

[9] Breda, T. and Napp, C. 2019. Girls' comparative advantage in reading can largely explain the gender gap in math-related fields. Proc. Nat. Acad. Sci. 116: 15435-15440.

[10] Fryer, R. G. and Levitt, S. D. 2010. An empirical analysis of the gender gap in mathematics. Am. Econ. J.: Appl. Econ. 2: 210-240. 